\title{
ORIGENS DOS INSTRUMENTOS DE FORMULAÇÃO DA POLÍTICA COMERCIAL NORTE-AMERICANA ${ }^{1}$
}

\author{
Tullo \\ Vigevani \\ Marcelo Fernandes de \\ Marcelo Passini \\ Oliveira \\ Mariano \\ Universidade Estadual Paulista Universidade de São Paulo Universidade Estadual Paulista
}

\section{RESUMO}

O objetivo do artigo é demonstrar a existência de evidências históricas que permitem estabelecer relações entre os conceitos de livre-comércio e protecionismo, ambos utilizados na política de comércio exterior dos Estados Unidos. Ao mesmo tempo, busca evidenciar a importância da legislação e dos princípios formulados nesse país e seu papel explicativo nas motivações da estrutura do comércio internacional após 1945. Esse papel explicativo contribui decisivamente para a compreensão das rodadas de negociações do GATT (General Agreement on Tariffs and Trade) até a criação da OMC (Organização Mundial de Comércio) em 1995. Do mesmo modo, demonstram-se as razões pelas quais o comércio internacional nos Estados Unidos é, além de questão de Estado, questão da sociedade.

PALAVRAS-CHAVES: Estados Unidos; política de comércio exterior; livre-comércio; protecionismo; Congresso norte-americano.

\section{INTRODUÇÃO}

O papel desempenhado pelo comércio internacional no desenvolvimento econômico é um tema amplamente discutido, e a busca de sua compreensão tem origens remotas; estudos clássicos realizados por Smith, Ricardo e Marx fazem numerosas referências a ele. Nos Estados Unidos, o debate iniciou-se com a Independência, ou mesmo antes, quando os Federalistas perceberam sua importância, tendo Hamilton, em 1787, discutido seu significado, relacionando-o à importância da criação de um grande Estado nacional. Seu artigo intitulado A utilidade da União no tocante ao comércio e à Marinha (HAMILTON, 1993) mostra como o comércio internacional poderia tornar-se instrumento de poder na busca do espaço mundial que, naquela fase, apenas os europeus detinham. Para os norte-americanos, a perseguição desse objetivo foi e tem sido uma constante.

${ }^{1}$ Este artigo resulta do projeto da Universidade Estadual de Campinas (UNICAMP) e do Centro de Estudos da Cultura Contemporânea (CEDEC), sob a coordenação de Sebastião Velasco e Cruz, Reestruturação econômica e reformas liberalizantes nospaíses em desenvolvimento a apoiado pela Fundação de Amparo à Pesquisa do Estado de São Paulo (FAPESP).
Para compreender as origens da política comercial dos Estados Unidos, abordaremos rapidamente o significado das relações econômicas internacionais e o papel do comércio. Nesse sentido, pretendemos analisar como estruturou-se ao longo do tempo, nos Estados Unidos, a formulação das políticas de comércio e, de modo geral, as relações econômicas externas. Pelo papel que vem desempenhando tanto na formulação como na execução dessas políticas, a análise dos momentos iniciais da USTR (United States Trade Representative) estará no centro deste texto.

Discutir a política comercial dos Estados Unidos é especialmente relevante porque ela contribui, de modo decisivo, para a compreensão de mudanças no cenário internacional. $\mathrm{O}$ vínculo entre a lógica nacional norte-americana e suas consequiências externas deve ser compreendido histórica e estruturalmente, a fim de que detenhamos os instrumentos analíticos adequados.

\section{SÍNTESE HISTÓRICA}

Ao findar a Segunda Guerra Mundial, iniciaramse inúmeros debates sobre qual deveria ser o modelo de desenvolvimento a adotar-se para a reconstrução econômica, particularmente dos países que 
permaneceriam no quadro do regime capitalista. $\mathrm{O}$ antecedente político desses debates pode ser situado na reunião realizada entre Roosevelt e Churchill, de 9 a 12 de agosto de 1941, em Terranova, na costa canadense, quando se fixaram, sob a forma de um documento intitulado "Carta do Atlântico", alguns princípios que deveriam reger as relações internacionais após o fim da guerra. Dentre esses princípios ressaltam-se: nenhuma expansão colonialista; nenhuma busca de expansão territorial; autodeterminação; livre acesso às matérias-primas; colaboração para o desenvolvimento econômico e social, e liberdade dos mares.

Como se pode perceber, nesses princípios ficou claramente subentendida a idéia de livre-comércio, já que o comércio administrado foi considerado pelos governos norte-americano e britânico como um dos fatores responsáveis pelo agravamento das tensões internacionais no período anterior a 1939 (DUROSELLE, 1970). Depois de 1947, como sabemos, a cláusula de nação mais favorecida tornouse o princípio básico a partir do qual se apoiaram todas as negociações comerciais internacionais do pós-guerra, o que se justificava, no aspecto econômico, por tratar-se de um conceito que se ajustava perfeitamente ao entendimento político que os norte-americanos tinham de quais deveriam ser as bases mínimas para o estabelecimento de maneiras internacionais cooperativas.

Partindo das considerações segundo as quais "o nível nacional e o internacional devem ser integrados na explicação" (CRUZ, 1999, p. 20), e de que a reestruturação econômica global consiste em um processo de mudanças que ocorrem simultânea e independentemente nos níveis nacional e internacional, torna-se fundamental a compreensão das motivações da política externa comercial dos Estados Unidos, não apenas por sua própria relevância, mas também por sua incidência na formação dos regimes internacionais e na ação das organizações multilaterais. Como ressaltamos, para os norte-americanos o comércio consiste em um dos elementos constitutivos da nação; por isso mesmo, até mais do que do próprio Estado, ele é um assunto da sociedade.

A Constituição norte-americana, em seu artigo primeiro, atribui ao Congresso o poder de regular o comércio com as nações estrangeiras e de estabelecer e arrecadar taxas e tarifas. Diversas análises sobre o comércio exterior dos Estados Unidos indicam residir aí o principal ponto de partida através do qual se explica a complexidade da formulação desse comércio, de seus mecanismos decisórios e, conseqüentemente, de sua própria compreensão. De acordo com O'Shea (1993), uma conseqüência do importante papel dos legisladores é a lógica muitas vezes contraditória dos processos decisórios. O poder dos grupos organizados - que em várias ocasiões podem estar em conflito - refletese na legislação e nas decisões adotadas; cada um deles intervém em determinadas situações, ainda que nem sempre o façam. Obviamente, como veremos, essa intervenção ocorre quando seus interesses estão em jogo.

Uma tese importante, repetidamente lembrada e que tem origem nos estudos de Gourevitch (1978), ampliados por Rogowski (1990) e Midford (1994), sugere ser o comércio exterior um fator extremamente relevante nas alianças políticas nacionais. Como já discutimos (VIGEVANI, 1998), essa assertiva deve ser relativizada, inclusive na análise das coalizões políticas dos Estados Unidos, visto que a distribuição dos custos e dos benefícios do livre-comércio e do comércio protegido ocorre de modo desigual entre as classes sociais, empresas e regiões, havendo portanto muitas ocasiões em que não é o comércio o fator central na determinação dessas alianças políticas. Em geral, empresas e trabalhadores prejudicados pela abertura comercial tendem a mobilizarse mais rapidamente que aqueles favorecidos por ela; ao longo da história norte-americana da segunda metade do século XX, podemos observar que os interesses mobilizados foram aqueles que tiveram muito a perder ou muito a ganhar. Em diversos casos, em razão dos efeitos difusos do comércio internacional, perceptíveis apenas a longo prazo, coube ao Estado encampar as decisões estratégicas adotadas.

Ao longo do século XX, o Congresso dos Estados Unidos inclinou-se ao protecionismo, o que pode ser atribuído à capacidade de pressão de grupos com interesses definidos. No geral, o discurso do livre-comércio foi atributo de setores do aparelho de Estado e, como veremos, foi assimilado pelo Congresso em determinadas circunstâncias, ligadas especialmente à possibilidade concreta de transformá-lo em vantagens bem definidas. Para os norte-americanos, algumas razões históricas consolidaram no governo e em atores relevantes a opção pelo livre-comércio, além daquele motivo, geral mas não menos verdadeiro, de que essa opção foi adotada quando a economia, a moeda e o poder político e estratégico apontaram ser este o caminho que levaria à constituição da hegemonia. 
Em 1930, logo no início da Grande Depressão, o Ato Smoot-Hawley resultou da premissa majoritária no Congresso - segundo a qual a solução para a crise ocorreria por meio da adoção de um acentuado protecionismo. Criticado por autores já nos anos 30 (SCHATTSCHNEIDER, 1935), esse caminho teria sido um dos fatores que contribuíram para a eclosão das guerras comerciais daquela década, tendo indiretamente estimulado os nacionalismos fascistas e, finalmente, levado à guerra (O'SHEA, 1993).

Dessa forma, no quadro das análises prevalecentes nos Estados Unidos no final da Segunda Guerra Mundial, elaboradas tanto pela administração como pela academia, as lições que se extraíram do Ato de 1930 acabaram modelando o conjunto de propostas a serem adotadas no âmbito do comércio internacional. Assim, fortaleceu-se o entendimento de que se as políticas restritivas em relação ao comércio tiveram como conseqüência a guerra, a adoção de um regime de comércio internacional liberal teria como consequiência a promoção da paz. A existência de debates entre essas duas posições nos Estados Unidos no início da década de 1930, se, por um lado, tem como causa a preocupação com o protecionismo e com o comércio administrado, por outro reflete a crescente capacidade competitiva do país, resultante tanto de seu poder econômico como do poder estratégico que vinha crescentemente desempenhando, apesar do isolacionismo em que ainda permaneceu na primeira parte das administrações Franklin Delano Roosevelt. É nesse quadro que vai fortalecendo-se a crença na necessidade de serem criados instrumentos para a promoção do livre-comércio(DESTLER, 1992), e que despontará ao final da Segunda Guerra Mundial como plenamente hegemônica nos Estados Unidos.

Nessa perspectiva, já em meados da década de 1930 introduziram-se mudanças no sistema de formulação da política de comércio exterior, que resultaram na delegação, pelo Congresso, de alguns poderes ao governo, sem, contudo, eliminar o papel desempenhado por ele próprio como responsável final por essa política. Com a aprovação do Reciprocal Trade Agreements Act de 1934, o Congresso atribuiu ao Presidente autoridade para agir em seu nome nas negociações para reduções tarifárias recíprocas na relação com outros países. Uma interpretação corrente a respeito do Ato de 1934 consiste em atribuir essa decisão ao desejo dos congressistas de evitar as constantes pressões de grupos de interesses específicos; ao delegar ao
Presidente a responsabilidade pela condução ordinária dos negócios de comércio exterior, o Congresso acabou redirecionando essas pressões para onde elas poderiam ser melhor administradas. De qualquer modo, ele continuaria exercendo um papel central, na medida em que os limites e o quadro de referência da ação do Executivo continuariam sendo determinados por ele. Pelo Ato de 1934, o Congresso continuava a deter o controle das ações específicas no campo do comércio, podendo alterar as condições de concessão de poderes por ocasião da renovação do mandato, ou mesmo retirá-los inteiramente. Exatamente por isso, a Presidência manteve-se sempre atenta e sensível aos anseios do Congresso.

É interessante analisar os antecedentes da política de comércio exterior dos Estados Unidos porque é neles que se encontram as raízes que fundamentam os comportamentos atualmente vigentes. $\mathrm{O}$ Congresso continuou respondendo às pressões da sociedade e dos grupos de interesse, mas transferiu a responsabilidade por sua administração ao Executivo, que lhes é menos permeável, sem, contudo, ser insensível às forças políticas. Essas pressões criaram um referencial que obrigou a constituição de um conjunto de regras e instituições.

Nos primórdios do atual sistema de formulação da política de comércio exterior dos Estados Unidos, as pressões eram dirigidas sobretudo a duas instituições, constituídas especialmente para administrá-las. A primeira era uma agência regulatória com caráter semijudiciário que ofereceu assistência a algumas empresas ou setores afetados pelas importações, de modo a diluir pressões de tipo protecionista. A segunda era um lead trade negotiator ("negociador comercial líder") - ou executive broker ("operador executivo") -, cuja função era manter o equilíbrio entre as pressões para o aumento de restrições às importações e as pressões favoráveis à expansão das exportações.

Com relação aos antecedentes que nortearam o interesse pelas relações econômicas externas, podemos assinalar que algumas leis, que remontam ao início do século $\mathrm{XX}$, concederam às empresas norte-americanas a possibilidade de buscar reparações ou indenizações nos casos em que os governos estrangeiros dessem apoio às suas próprias empresas. Nesses casos, a empresa norteamericana poderia pedir ao governo a aplicação de taxas alfandegárias em retaliação - countervailing duty (CVD) - com o objetivo de compensar as 
eventuais vantagens decorrentes dos subsídios. Nessa mesma linha, em 1921 estabeleceram-se dispositivos antidumping visando à compensação por meio de taxas nos casos em que empresas estrangeiras estivessem praticando nos Estados Unidos preços mais baixos que aqueles praticados em seus próprios países, ou vendendo a preços inferiores ao custo acrescido de uma margem de lucro considerada razoável. Como se sabe, todos esses procedimentos foram posteriormente assimilados às regras do General Agreement on Tariffs and Trade (Acordo Geral sobre Comércio e Tarifas-GATT).

O que importa registrar é que, como vimos, desde 1934 houve uma decisão do Congresso americano no sentido de delegar ao governo um efetivo papel na gestão do comércio exterior, sem perder seu controle político. Surgiu a partir daí uma questão recorrente nessa área da política do país: a da busca do atendimento aos interesses setoriais, corporativos, de cadeias produtivas, de regiões geográficas, de grupos e de classes e, ao mesmo tempo, uma constante atenção do Executivo e da Presidência às questões políticas, estratégicas e militares.

Para O'Shea (1993), foi a partir da dualidade apontada - a sobreposição de poderes no tocante ao comércio e à economia internacional - que surgiu a necessidade de criar-se uma agência mais abrangente, capaz de administrar o comércio e de relacionar-se com o Congresso, portanto com poder executivo, mas com fonte diversificada de legitimidade. Mais que isso, surgiu a necessidade de criar-se um sistema capaz tanto de relacionar-se com as diversas agências envolvidas com o comércio, como de representar a diversidade de interesses em relação à política econômica externa.

Nessas circunstâncias, na primeira metade do século XX, a instituição que assumiu a liderança do processo e foi responsável seja pelas relações Executivo-Legislativo nesse campo, seja pela busca da formação do consenso interno à própria administração e no país, bem como pela liderança nas negociações bilaterais e multilaterais, foi o Departamento de Estado, que se tornou campeão do livrecomércio, considerado a grande fortaleza da política exterior dos Estados Unidos. Como veremos, a partir dos anos 1950 o Congresso passou a considerar inadequado o papel de principal agência da política de comércio exterior desempenhado pelo Departamento de Estado, visto que, além do comércio, ele administrava também o conjunto das relações externas, tornando-se portanto vulnerável a outros interesses que, em alguns casos, sobrepujavam aqueles especificamente comerciais. No que se refere aos interesses comerciais, os atores internos mobilizavam-se com forte capacidade de influência, criticando a insuficiente ação do Departamento de Estado.

\section{O PÓS-SEGUNDA GUERRA MUNDIAL}

Durante a Segunda Guerra Mundial, sobretudo após a conferência de Teerã, de novembro de 1943, enquanto as negociações relativas ao reordenamento político e estratégico do sistema internacional tinham como base as relações entre os Estados Unidos, a Grã-Bretanha e a União Soviética, a que incorporaram-se lentamente outros países, as discussões sobre o reordenamento econômico centraram-se sobretudo nos Estados Unidos, ainda que no contexto de suas relações com outros estados. Depois de Ialta, em fevereiro de 1945, e de Potsdã, em julho de 1945, as relações norteamericanas com os países da Europa Ocidental e Central foram gradativamente aumentando de importância; alguns anos mais tarde, ganhou relevância também a relação do país com o Japão. O Plano Marshall, formulado de junho a setembro de 1947, comprovou o papel atribuído pelos Estados Unidos à Europa capitalista.

Deve-se assinalar o significado desse período para a melhor compreensão da política liberal e multilateralista que apoiou o sistema do GATT e que acabou sendo realimentada em alguns aspectos, mesmo quando o ambiente internacional havia-se modificado profundamente, já nos anos 1980 e 1990. Sob a vanguarda de indústrias novas e de uma ampla renovação do sistema financeiro, adotou-se, a partir dos anos 1970 e mais acentuadamente nos 1980 e 1990, "uma postura eminentemente 'ofensiva': uso agressivo do poder do Estado para 'abrir mercados' e exigir de outros países a adoção de leis, instituições e práticas consonantes [sic] com os interesses das empresas americanas" (CRUZ, 1999, p. 29). Isto é, mantendose constante o princípio do multilateralismo, ele efetivamente associou-se a outros instrumentos de caráter multilateral e a outros acentuadamente bilaterais ou unilaterais.

Pode-se compreender melhor a importância dos anos imediatamente posteriores à Segunda Guerra Mundial se levarmos em conta a vantagem diferencial que se pode obter por um ator com peso sufi- 
ciente para modelar o sistema à sua lógica de atuação e torná-lo funcional às suas competências. Mesmo sem aceitar a premissa neo-realista de Waltz (1987), para quem o fato de a estrutura selecionar implica "dizer que os que se conformam às práticas mais difundidas e coroadas de sucesso chegam mais freqüentemente ao topo e têm probabilidade de nele permanecer", cabe reconhecer o papel significativo desempenhado pelas estruturas. Ressalte-se que, tendo em vista toda a crítica neoliberal e construtivista em torno do tema, conhecemos os limites dessa análise. De todo modo, a conclusão do autor, de que "o jogo a ser vencido é definido pela estrutura e ela determina o tipo de jogador que tem mais probabilidade de vencer" (idem, p. 185) não pode ser totalmente desprezada na medida em que ajuda a compreender o significado do momento fundante do sistema econômico pós-Segunda Guerra Mundial e que colocou os Estados Unidos no centro. Essa posição "solar", ainda que intensamente questionada e modificada nas décadas seguintes, teve significado na explicação das razões por que o país continuou a manter uma posição central no sistema econômico. O fato de, em 1945, os Estados Unidos representarem aproximadamente $50 \%$ da produção mundial explica e fundamenta as razões daquela estrutura inicial, mesmo considerando-se que grande parte da sua produção era consumida no próprio país. Dos US\$ 33 bilhões de reservas em ouro existentes em todo o mundo, US\$ 20 bilhões pertenciam aos Estados Unidos. Ao final da Segunda Guerra Mundial, mais da metade da capacidade do transporte marítimo internacional pertencia também àquele país, e aproximadamente um terço das exportações mundiais provinham dele. Ainda assim, até 1960 o grau de abertura de sua economia era pequeno e o peso do comércio internacional em relação ao produto era baixo, não passando de um dígito.

No entanto, o peso mundial que o país detinha deve ser medido por outros fatores, particularmente pelos seus investimentos no exterior (DOBSON \& MARSH, 1994). Mesmo tendo gradativamente diminuído seu peso, declinando para aproximadamente $25 \%$ do produto mundial em 2000 , seu papel no sistema pode ter-se modificado, mas o papel central que desempenhava não se alterou significativamente. É verdade que essa posição "solar" não se manteve de maneira automática, apenas em razão da posição estrutural ocupada pelo país, como poderiam concluir os neo-realistas, mas foi obtida por meio de intenso processo de negocia- ções internacionais e de adaptações, em diferentes setores, no policy making interno, particularmente no âmbito das políticas de comércio exterior.

Como salientamos, no período pós-Segunda Guerra Mundial desenvolveu-se intensa discussão sobre qual deveria ser o novo modelo de desenvolvimento a ser adotado para a efetiva reconstrução da economia capitalista. Entre as propostas que ganharam relevância no debate predominou, no âmbito interno, aquela que visava a consolidar um ciclo virtuoso de crescimento econômico baseado no fordismo como modelo de produção e na intervenção do Estado na economia, tanto como gerador de infra-estrutura básica quanto de provedor direto e indireto de capitais a baixos custos. $\mathrm{O}$ Estado seria também responsável pela criação e sustentação de uma ampla rede de benefícios sociais à sua população, que viabilizaria aquele círculo virtuoso tendo como pressuposto a continuidade do consumo. O objetivo dessa estratégia era gerar desenvolvimento, tendo como base a manutenção constante de demanda, ou seja, a procura por novos produtos incentivaria as empresas a investir crescentemente na produção, seja para o aumento de escala, seja para a renovação tecnológica. A inventividade associada à produção de novos produtos para o mercado traria retorno em termos de remuneração do capital pela ampliação do mercado associado à emergência de consumidores que viviam, nos Estados Unidos, num contexto de pleno emprego e com benefícios sociais relativamente garantidos pelo Estado.

Pelo menos até a metade dos anos 1960, foi possível a retroalimentação desse ciclo, o que levou Hobsbawm (1995) a considerar esta fase como a "Era de Ouro do capitalismo"; para outros, ela foi denominada "os vinte e cinco gloriosos". É verdade que, no mesmo período, a prevalência dos Estados Unidos no plano político foi contestada em diferentes terrenos, mas a força econômica do sistema revelou-se efetiva e não pareceu ameaçada pela diminuição relativa do peso do país. O ressurgimento europeu ocidental e japonês, ainda nos anos 1950, apenas serviu para mostrar o vigor da economia mista, ou do embedded capitalism, o capitalismo regulado. Os instrumentos com que passou a contar a economia no pós-Segunda Guerra Mundial, sob a liderança dos Estados Unidos, devem também ser parcialmente atribuídos à elaboração intelectual que surgiu na esteira das consequiências da crise iniciada em 1929. Alguns dos pressupostos são anteriores, como sugere a obra de Keynes (2002), 
As conseqüências econômicas da paz, publicada em 1919. A partir daí, o New Deal e novas formulações econômicas, várias delas contidas na obra mais conhecida de Keynes (1983), Teoria geral do emprego, do juro e do dinheiro, publicada em 1936, pavimentaram o caminho pós-1945. Como lembra Moraes, "segundo a teoria keynesiana, o Estado deveria manejar grandezas macroeconômicas sobre as quais era possível acumular conhecimento e controle prático. O poder público, desse modo, regularia as oscilações de emprego e investimento, moderando as crises econômicas e sociais [...]. Esse era o chamado 'consenso keynesiano', que se tornaria avassalador no pósguerra" (MORAES, 2001, p. 29-30).

Como já indicamos, o vigor desse ciclo virtuoso vinculou-se à possibilidade de manutenção do equilíbrio macroeconômico internacional e das regras de comércio e de relações econômicas internacionais que lhe garantissem fluidez. Para os Estados Unidos, o papel do comércio é muito importante, mas não se deve esquecer que o país consolidou seu poder econômico contando sobretudo com seu mercado interno, fortemente protegido até os primeiros anos do século XX. Em alguns setores, ele continua protegido ainda hoje, embora de modo diferente do tradicional. É exatamente na relação entre a economia nacional e o comércio internacional que se têm centrado as análises críticas dos globalistas nos anos 1980 (ROSECRANCE, 1986). As mudanças nas atitudes norte-americanas frente ao comércio exterior explicam também as mudanças nas estruturas internas por meio das quais sua política é elaborada e executada.

Os acordos de Bretton Woods, de julho de 1944, previram a necessidade de se aumentar a cooperação entre os países capitalistas na economia mundial, visando tanto à ampliação do comércio internacional quanto à criação dos instrumentos institucionais para um modelo de desenvolvimento que evitasse os erros da desordem econômica, do protecionismo, da não-conversibilidade monetária e do comércio administrado. Para atingir estes objetivos, foram discutidas em Bretton Woods as diretrizes para a criação de três grandes instituições internacionais: o Fundo Monetário Internacional (FMI), o Banco Mundial (BIRD) e a Organização Internacional do Comércio (OIC).

De fato, no acordo de julho de 1944 estabeleceram-se os princípios de funcionamento do FMI.
Seu papel seria manter a estabilidade das taxas de câmbio e auxiliar, por empréstimos financeiros especiais, os países com dificuldades em seu balanço de pagamentos. O objetivo seria evitar que esses países, ao entrarem em situação de crise financeira devido a desequilíbrios em suas contas internas ou externas, restringissem o comércio lançando mão de desvalorizações cambiais na tentativa de equilibrar suas contas. O BIRD teria como funções tanto garantir recursos suficientes para a reconstrução dos países atingidos pela guerra quanto promover e apoiar projetos de desenvolvimento dos países que a ele recorressem. Nos dois casos, é importante notar que o regime decisório instituído vinculava-se diretamente às cotas de capital que cada país detinha e detém na instituição. Desse modo, o papel dos Estados Unidos ganhou relevância, condicionando o próprio funcionamento dessas instituições, cujas sedes estabeleceram-se em Washington, como conseqüência inclusive da cota-parte de capital detida pelo país. O papel exercido pelas organizações internacionais no estabelecimento da agenda e seu uso funcional por parte dos atores públicos e privados mais influentes têm sido amplamente discutidos (MURPHY, 1994; CRUZ, 2000).

Da mesma forma que a Organização das Nações Unidas, o FMI e o BIRD foram criados e iniciaram o seu efetivo funcionamento logo após o término da guerra. Formalmente, esses órgãos têm vínculos com a ONU, ainda que frágeis; eles constituem Instituições Especiais do Conselho Econômico e Social daquela Organização. O BIRD foi criado em dezembro de 1945 e o FMI em 1946.

A história da OIC é muito diferente. Sua tarefa seria estabelecer e fazer funcionar um novo regime para o comércio internacional, baseado nos princípios da democracia, do liberalismo e do multilateralismo. A conferência internacional para sua criação realizou-se em Cuba, de novembro de 1947 a março de 1948, quando se negociaram os termos para sua implantação e funcionamento, e que resultaram na Carta de Havana. Esse documento nunca foi ratificado pelos Estados Unidos, visto que a grande maioria dos congressistas receava que ele restringisse a soberania do país no tocante ao comércio internacional. Acrescente-se o fato de que o Congresso era constitucionalmente detentor dos poderes em relação ao comércio internacional e não parecia disposto a delegá-los ao governo e ao Presidente. Ressalte-se que a não-abdicação de qualquer espécie de poder de soberania era questão 
essencial para o Congresso, tendo sido objeto de discussão no final de 1944 no tocante às Nações Unidas. O sistema de veto no Conselho de Segurança, que assegura aos membros detentores desse poder a inexistência de qualquer risco para a própria soberania nacional, acabou permitindo a superação das dificuldades de ratificação pelo Congresso norte-americano do acordo da Conferência de São Francisco que aprovou a carta das Nações Unidas, em junho de 1945. O voto por meio de cotas no FMI e no BIRD também garantia a segurança considerada necessária pelos Estados Unidos. A resolução do impasse resultante da não ratificação pelo Congresso dos Estados Unidos da Carta de Havana ocorreu em 1948, por meio de um Acordo Provisório entre 23 países, dentre os quais os Estados Unidos. Por este Acordo ficou estabelecida a adoção de um único segmento da Carta de Havana - o de Política Comercial (Capítulo IV) -, relativo às negociações de tarifas e regras sobre o comércio internacional; mais tarde, ele passou a ser denominado Acordo Geral sobre Tarifas e Comércio (General Agreement on Tariffs and Trade GATT). Esse Acordo Provisório foi possível pelo fato de o Congresso ter autorizado o poder Executivo a assinar acordos dessa natureza.

Depois de 1947, segundo Abreu (1998), o GATT tornou-se efetivamente, pelo direito consuetudinário, embora não legalmente, um órgão internacional. Com sede em Genebra, forneceu sistematicamente a base institucional para a consolidação de diversas rodadas de negociações multilaterais sobre comércio internacional, zelando por seu efetivo cumprimento até o final da Rodada Uruguai, concluída com a criação da Organização Mundial do Comércio (OMC), em 1995. Tanto o GATT quanto a OMC tiveram e têm o objetivo de liberalizar o comércio entre os países-membros. As prescrições básicas do GATT incluíam a abolição do uso de cotas, assim como de restrições quantitativas ou quaisquer outras barreiras ao comércio internacional, sendo as tarifas aduaneiras o único instrumento permitido, com a condição de serem paulatinamente reduzidas.

Como apontamos, a adoção da Cláusula de nação mais favorecida (GATT, 1986, Art. I), que imprime caráter multilateral ao GATT e proíbe a discriminação entre as suas partes contratantes qualquer vantagem, favor, privilégio ou imunidade no tocante às tarifas aduaneiras de um produto proporcionados a um país-membro devem ser instantânea e incondicionalmente estendidos a qualquer outro participante -, acabou sendo sua marca fundamental. Ao mesmo tempo, desde a criação do GATT decidiu-se a redução progressiva de tarifas alfandegárias com base na negociação de uma Lista de Concessões Recíprocas a serem acordadas em rodadas sucessivas de discussões multilaterais. No quadro dessa negociação, determinou-se a lista dos produtos e das tarifas máximas que devem vigorar no comércio internacional; essa lista é levada em consideração para estabelecer o padrão mínimo de benefícios a serem mutuamente oferecidos pelas partes contratantes, podendo ser alterada por de maiores concessões aos interessados (idem, Art. II).

Sem dúvida, as regras do GATT corresponderam à aceitação internacional dos critérios liberais defendidos pelos Estados Unidos no período final da Segunda Guerra Mundial e nos anos subseqüentes. Poder-se-ia afirmar que esses critérios resultam de uma aplicação da teoria clássica do comércio internacional, de Ricardo, aplicada no quadro da visão keynesiana da economia política. Paulatinamente, introduziram-se nas relações econômicas internacionais os mecanismos que a legislação norte-americana vinha construindo desde o início do século XX: os instrumentos legais de aplicação do antidumping, o sistema de cotas - que não seria abolido - e as medidas de caráter retaliatório.

Segundo Thorstensen (2001), para atender a interesses específicos das partes contratantes; para evitar que o sistema fosse burlado por meio da utilização de outros instrumentos que não os permitidos pelo acordo, e para garantir um processo de transição equilibrado, foi necessário admitir algumas exceções a essas regras, que foram incorporadas pelo GATT sob a forma de Exceções Gerais (GATT, 1986, Art. XX); de Salvaguardas ao Balanço de Pagamentos (idem, Art. XII); de Salvaguardas ou Ações de Emergência sobre Importações (idem, Art. XIX); assim como de exceções nos casos das Uniões Aduaneiras e Zonas de Livre-comércio (idem, Art. XXIV) e nos casos denominados como Comércio e Desenvolvimento (idem, Parte IV). Essa institucionalidade básica no GATT permitiu o aperfeiçoamento desse sistema de regras de comércio internacional, viabilizando também a realização das rodadas de negociações multilaterais. As seis primeiras - Genebra, 1947; Annency, 1949; Torquay, 1951; Genebra, 1956; Rodada Dillon, de 1960 a 1961; Rodada Kennedy, de 1964 a 1967 - tiveram como objetivo principal 
a negociação de concessões tarifárias recíprocas; as duas últimas foram mais amplas: Rodada Tóquio, de 1973 a 1979, e a Rodada Uruguai, de 1986 a 1994. Está em curso uma nova rodada, chamada do Milênio ou de Doha, iniciada em reunião de ministros de Comércio Exterior dos países membros da OMC realizada em novembro de 2001. Essa Rodada, prevista para concluir-se em 2005, também tem como objetivo ser abrangente.

Parece haver significativo consenso no reconhecimento de que, entre 1947 e 1967, sobretudo no tocante à troca de concessões, o GATT foi efetivo principalmente nas relações entre os países desenvolvidos, enquanto os países em desenvolvimento, por disporem de menor capacidade de influência, participavam dessas negociações visando a alguns benefícios marginais, dentro da lógica de free-riders ("caronistas"). Nesse período, muitos consideravam o GATT um clube de países ricos, interessados no seu próprio desenvolvimento. Como vimos, esse processo era centrado numa capacidade de reprodução ampliada, em todos os campos, e já incluía toda a Europa Ocidental e o Japão desde o início dos anos 50. As seis primeiras rodadas trataram sobretudo da diminuição dos direitos alfandegários de produtos industrializados por meio da negociação de concessões tarifárias recíprocas, o que aparentemente pouco interessava aos países subdesenvolvidos. Seus resultados foram promissores para os países centrais, já que levaram a um substancial aumento do comércio internacional nesse período.

Contudo, de maneira sintética, assinale-se que a partir dos anos 1960 o ciclo virtuoso do modelo de desenvolvimento utilizado no pós-1945 começou a apresentar limites, passando a gerar ininterruptamente uma sobrecapacidade industrial. Isso resultou de motivos diversos, mas principalmente do significativo investimento em tecnologia, visando a economias de escala. Como seria de se esperar, o comércio internacional passou a ganhar novas dimensões nas discussões, apresentando-se como possível solução para o impasse. Não se tratava mais, como nos debates clássicos, de aumentar os mercados, mas de criar-se um novo padrão na economia mundial, que passaria a refletir-se em novas formas de estruturação das empresas.

Foi nesse contexto que realizou-se, em 1964, a Rodada Kennedy, ainda fortemente voltada para rebaixamentos tarifários por meio de concessões recíprocas. A novidade dessa rodada foi a preocupação em incorporar ao GATT novos membros, sobretudo de países em desenvolvimento. Esse objetivo foi alcançado, tendo o número de participantes, que até aquele momento era de 26 , aumentado para 62. Sem se restringir a este aspecto, o salto no número de Estados participantes do GATT resultou também em forte ampliação no valor do comércio objeto de negociações, como mostra a Tabela 1.

\section{TABELA1-RODADASDENEGOCIAÇÕES DO GATT}

\begin{tabular}{|l|c|c|c} 
Data & Local da rodada & $\begin{array}{c}\text { N. de países } \\
\text { participantes }\end{array}$ & Comércio em US\$ \\
\hline $1-1947$ & Genebra (Suíça) & 23 & 10,0 bilhỗes \\
$2-1949$ & Annecy (França) & 13 & n.d. \\
\hline $3-1951$ & Torquay (Reino Unido) & 38 & n.d. \\
$4-1956$ & Genebra (Suiça) & 26 & 2,5 bilhôes \\
\hline $5-1960-1961$ & Rodada Dillon & 26 & 4,9 bilhỗes \\
$6-1964-1967$ & Rodada Kennedy & 62 & 40,0 bilhỗes \\
\hline $7-1973-1979$ & Rodada Tóquio & 102 & 155,0 bilhốes \\
$8-1986-1994$ & Rodada Uruguai & 123 & 3,7 trilhôes \\
\hline
\end{tabular}

FONTE: Thorstensen (2001, p. 31).

NOTA: $n$. d. = não disponível.

Além da sinergia entre os mercados dos países centrais - principal objetivo a ser alcançado -, buscava-se incorporar os países em desenvolvimento visando à ampliação do mercado. Essa incorporação não tinha como objetivo uma significativa expansão do consumo, tendo em vista a capacidade de compra relativamente reduzida desses países; no entanto, a agregação de peque- 
nos percentuais de mercado é bastante significativa na estratégia empresarial das grandes empresas. Mesmo sendo levados a aderirem mais intensamente às regras internacionais de comércio com sua inclusão no GATT, nos anos 1960 e 1970 muitos desses países buscavam implantar projetos de desenvolvimento baseados na intervenção do Estado na economia e na ampliação de seus parques produtivos nos moldes do modelo fordista. Com diferentes ritmos e sobretudo com políticas de desenvolvimento, de adequação competitiva e de comércio exterior distintas, eles buscavam substituir importações protegendo seus mercados com elevadas tarifas alfandegárias e, em certos casos, com rígidos controles sobre o mercado de capitais. Em alguns países, os instrumentos utilizados não eram as tarifas ou o controle dos fluxos de capital, mas outros instrumentos públicos que foram inicialmente permitidos pelo GATT durante um período transitório visando à adequação desses países. Entre esses instrumentos, um bastante importante foi o princípio da infant industry ("indústria nascente").

A intensificação das dificuldades de compatibilização entre a inserção e o desenvolvimento acabou por se refletir nas organizações internacionais. A criação, em 1964, da Conferência das Nações Unidas sobre Comércio e Desenvolvimento (UNCTAD) comprova esses reflexos. A regra do Tratamento Especial e Diferenciado do GATT (Parte IV) visou a incorporar parte das pressões. $\mathrm{Na}$ década de 1970, mas sobretudo na de 1980, a lógica subjacente à idéia de tratamento especial foi considerada - particularmente pelos Estados Unidos prejudicial às exportações dos países ricos, uma vez que tanto no mercado nacional como no internacional eles passaram cada vez mais a sofrer a competição alemã e japonesa, além daquela dos próprios países em desenvolvimento.

Portanto, podemos afirmar que, entre meados da década de 1960 e o início dos anos 1970, o ciclo virtuoso do modelo de desenvolvimento do pós1945, que havia sido eficaz tanto para a reconstrução das economias destruídas pela Segunda Guerra Mundial quanto para a consolidação da prevalência dos Estados Unidos entre os países capitalistas e para a relação com a União Soviética, alcançava seu limite, levando ao surgimento de fatores que contribuiriam para sua crise. Em termos de poder econômico, a participação do PIB (Produto Interno Bruto) norte-americano em relação ao mundial caiu de 40,1\% em 1965 para 29,2\% em 1981.

\section{POLICY MAKING NOS ESTADOS UNIDOS NOS ANOS 1950, 1960 E 1970}

Apesar de seu poder competitivo, as pressões protecionistas nos Estados Unidos nos anos que se seguiram à criação do GATT fizeram-se sentir, levando o Congresso a estabelecer formas quase judiciais de regulamentação. Para ajudar as empresas e os trabalhadores mais afetados por políticas de liberalização comercial, inclusive pelas políticas norte-americanas de baixas tarifas alfandegárias e, ao mesmo tempo, com o objetivo de impedir sua mobilização em favor de maiores mudanças de tipo protecionista na legislação de comércio, foram criadas instituições de regulamentação e regras especiais, com a introdução de um sistema de recursos que poderiam ser pleiteados pelos setores que se sentissem afetados por importações no quadro de duas categorias: a) um socorro temporário frente às importações, b) proteção contra práticas de comércio desleais.

Os Estados Unidos, que haviam influenciado alguns dos conceitos de referência negociados na Conferência de Havana - mantidos quando a organização ficou restringida ao GATT -, utilizaram adequadamente parte das regras para proteger seu próprio comércio. O Artigo 19 do GATT estabeleceu a escape clause, a cláusula de exceção, que foi utilizada para criar regras por meio das quais os interesses que se considerassem afetados por importações poderiam procurar o abrigo previsto na Seção 201 da Lei de Comércio. Para qualificar-se a obter esta proteção especial, as indústrias afetadas deveriam apresentar uma petição à Tariff Commission (Comissão Tarifária), depois denominada International Trade Commission (ITC Comissão do Comércio Internacional). Na petição e subseqüente audiência, elas deveriam provar: a) que houve efetivamente o prejuízo, e b) que ele concretizou-se em conseqüência da liberalização comercial. Caso a Comissão decidisse em favor da petição da empresa e recomendasse a proteção solicitada, o Presidente poderia determinar a aplicação de tarifas temporárias ou cotas sobre o produto importado que estaria acarretando o prejuízo, ou poderia negar a proteção argumentando que ela interferia em outros interesses norte-americanos.

Outras formas de defesa utilizadas foram a proteção contra as exportações subsidiadas pelo Estado e a proteção contra as práticas de dumping eventualmente adotadas por empresas estrangeiras. Como já examinamos, o princípio de retaliação 
utilizado pelos Estados Unidos nos casos em que um governo estrangeiro protegesse suas próprias empresas já vinha sendo incorporado à legislação desde o início do século XX, tendo sido aplicado mesmo depois da criação do GATT. De fato, o Artigo $6^{\circ}$ do GATT absorveu quase integralmente esses princípios, e eles passaram a ser considerados como regras normais do comércio internacional. As empresas dos Estados Unidos podiam solicitar ao próprio governo norte-americano a aplicação de uma taxa de retaliação - countervailing duty-, de modo a compensar as vantagens eventualmente obtidas em decorrência dos subsídios.

O final dos anos 1940 e os anos 1950 são considerados pela literatura como um período em que foi relativamente fácil para as indústrias recorrer a esses instrumentos de proteção quase judiciais e receber a cobertura desejada. A execução desses instrumentos era de responsabilidade compartilhada pelo Congresso e pelo governo. Nos anos 1960, porém, a abrangência desses instrumentos foi significativamente reduzida, e as regras e os procedimentos favoráveis às empresas norte-americanas eram mais raramente utilizados pelo Presidente por temer problemas no relacionamento com países aliados. Por outro lado, essa situação acabou levando a uma maior abertura econômica, que ocorreu às expensas de um crescente descontentamento das indústrias e debilitou a legitimidade dos mecanismos criados nos Estados Unidos no tocante ao comércio internacional. Nos anos 1970, o Congresso enfrentou essa questão introduzindo, por duas vezes, emendas às leis de comércio que fortaleciam as medidas relativas à proteção das empresas norte-americanas e introduziam medidas apropriadas que garantissem aquela proteção.

Para compreender-se o ambiente que surgiu nos anos 1970 e que se consolidou nos 1980, é necessário analisar as motivações do Trade Act de 1974, que ampliou os critérios por que as empresas podem recorrer ao Congresso e, ao mesmo tempo, torna mais difícil ao Presidente não conceder as medidas solicitadas pelas próprias empresas depois de uma decisão a elas favorável de parte da ITC. O Congresso também assinalou a necessidade de endurecimento na aplicação de barreiras nãotarifárias e na contenção de práticas de comércio desleal, o que implicou o fortalecimento das regras de aplicação das taxas de retaliação, as CVD, e das regras antidumping, como indica a seguinte passagem de uma audiência no Committee on Ways and Means (Comitê de Caminhos e Meios) da
Câmara dos Representantes dos Estados Unidos: "Hoje, o poder econômico não está concentrado somente nos Estados Unidos como acontecia há trinta anos. Grandes centros de riqueza cresceram na Europa e no Japão [...]. Apesar disso, juntamente com essa difusão de poder também houve relutância em remover restrições que são contrárias aos princípios de uma economia mundial aberta [...]. Nesse mundo diferente de economias semelhantes nós precisamos chegar a um acordo sobre essas restrições, e precisamos de novas regras para assegurar igualdade de responsabilidade" (BAYARD \& ELLIOT, 1992, p. 13).

Ainda nessa direção, o Congresso também fortaleceu e dinamizou o conceito de retaliação definido na seção 301 do Trade Act de 1974. Segundo O'Shea, “mais importante, porém, é que, em 1979, o Congresso forçou uma reorganização administrativa, delegando a autoridade relativa às medidas compensatórias e à análise do comércio desleal, até então atribuída ao Departamento do Tesouro, ao Departamento do Comércio, que tem sido tradicionalmente bem mais simpático aos interesses industriais dos Estados Unidos" (O'SHEA, 1993, p. 36).

Uma questão de caráter mais amplo, mas relevante na medida em que provavelmente explica as premissas que produzem as mudanças no policy making da política de comércio internacional nos Estados Unidos, é o fato de que as estruturas criadas no imediato pós-Segunda Guerra Mundial - inclusive o papel desempenhado pelo Departamento de Estado nos assuntos ligados ao comércio exterior - vão-se revelando ineficazes do ponto de vista dos empresários e dos partidos políticos. A partir de meados dos anos 1950, as economias dos outros países recuperaram peso e competividade, encontrando espaço no próprio mercado norte-americano. Buscando reagir a tal situação, em 1962 o Congresso criou o cargo de Special Trade Representative (STR), Representante Especial para o Comércio, alocado no Escritório Executivo da Presidência, e deu-lhe plenos poderes na coordenação da política de comércio. É relevante assinalar que, nos anos 1960 e no início dos 1970, o STR manteve-se razoavelmente preso à tradição liberal, de políticas internacionalistas, de acordo com o modelo que vinha sendo aplicado pelo Departamento de Estado (DESTLER, 1978). Como sabemos, o STR mudou sua denominação para United States Trade Representative (USTR Representante Comercial dos Estados Unidos) por 
ocasião da aprovação do Trade Act de 1974.

$\mathrm{O}$ que buscamos demonstrar, por meio desta reconstrução histórica, é a estreita relação entre os conceitos de livre-comércio e de protecionismo, ambos utilizados na política de comércio dos Estados Unidos. Ao mesmo tempo, acreditamos termos demonstrado a importância da legislação e dos princípios formulados nos Estados Unidos e seu papel explicativo das motivações da estrutura do comércio internacional pós-1945. Esse papel explicativo contribui decisivamente para a compreensão também das rodadas de negociações do GATT até a criação da OMC. Do mesmo modo, o artigo buscou demonstrar as razões por que o comércio internacional é, além de questão de Estado, questão da sociedade nos Estados Unidos.

Tullo Vigevani (vigevani@unesp.br) é Professor Livre-Docente na Universidade Estadual Paulista (UNESP), campus de Marília, e pesquisador do Centro de Estudos da Cultura Contemporânea (CEDEC).

Marcelo Fernandes de Oliveira (mfernandesoliveira@bol.com.br) é doutorando em Ciência Política na Universidade de São Paulo (USP) e pesquisador do CEDEC.

Marcelo Passini Mariano (marcelo-mariano@uol.com.br) é doutorando em Ciências Sociais na UNESP e pesquisador do CEDEC.

\section{REFERÊNCIASBIBLIOGRÁFICAS}

ABREU, M. P. 2001. O Brasil, o GATT e a OMC. Política Externa, São Paulo, v. 9, n. 4, p. 89-119.

BAYARD, T. \& ELLIOT, K. 1992. 'Aggressive Unilateralism' and Section 301 : Market Opening or Market Closing. Washington : Institute for International Economics.

CRUZ, S. C. V. (coord.). 1999. Reestruturação econômica mundial e reformas liberalizantes nos países em desenvolvimento. Fundação de Amparo à Pesquisa do Estado de São Paulo/Centro de Estudos da Cultura Contemporânea/Universidade Estadual de Campinas. Projeto temático: área: Ciência Política, processo 99/09639-5. Projeto em andamento. Início : 01.out.2001.

2000. Um outro olhar: sobre a análise gramsciana das organizações internacionais. Revista Brasileira de Ciências Sociais, São Paulo, v. 15, n. 42, p. 39-54, fev.

DESTLER, I. M. 1978. United States Policymaking during the Tokyo Round. In: BLAKER, M. (ed.). The Politics of Trade: US and Japanese Policymaking for the GATT Negotiations. New York : Columbia University.

DESTLER, I. M. 1992. American Trade Politics : System under Stress. $2^{\text {nd }}$ ed. Washington : Institute for International Economics.

DOBSON, A. P. \& MARSH, S. 1994. US Foreign Policy since 1945. New York : Routledge.
DUROSELLE, J.-B. 1970. Histoire diplomatique de 1919 à nos jours (1919-1970). Paris : Dalloz.

GOUREVITCH, P. 1978. The Second Image Reversed. International Organization, Cambridge (Mass.), v. 32, n. 4, Autumn.

HAMILTON, A. 1993. A utilidade da União no tocante ao comércio e à Marinha. In : MADISON, J., HAMILTON, A. \& JAY, J. Os artigos federalistas (1787-1788). Rio de Janeiro : Nova Fronteira.

HOBSBAWM, E. 1995. Era dos extremos. O breve século XX - 1914-1991. São Paulo : Companhia das Letras.

KEYNES, J. M. 1983. Teoria geral do emprego, do juro e do dinheiro. São Paulo : Abril Cultural.

.2002. As conseqüências econômicas da paz. São Paulo : Imprensa Oficial do Estado de S. Paulo.

MIDFORD, P. 1994. International and Domestic Politics : Improving on Rogowski's Model of Political Alignments. International Organization, Cambridge (Mass.), v. 47, n. 4, p. 535564, Autumn.

MORAES, R. 2001. Neoliberalismo : de onde vem, para onde vai? São Paulo : SENAC.

MURPHY, C. N. 1994. International organization and industrial change. Global governance 
since 1850. Cambridge : Polity Press.

O'SHEA, T. J. C. 1993. The Domestic Political Setting of US Trade Policy. In : WALTERS, R. S. (ed.). Talking Trade : US Policy in International Perspective. Boulder : Westview Press.

ROGOWSKI, R. 1990. Why Changing Exposure to Trade Should Affect Political Cleavages. In: . Commerce and Coalitions : How Trade Affects Domestic Political Alignments. Princeton : Princeton University Press.

ROSECRANCE, R. 1986. The Rise of the Trading State. New York : Basic.

SCHATTSCHNEIDER, E. E. 1935. Politics, Pres- sures and the Tariff. Englewood Cliffs : Prentice-Hall.

THORSTENSEN, V. 2001. OMC. As regras do comércio internacional e a nova rodada de negociações multilaterais. São Paulo : Aduaneiras.

VIGEVANI, T. 1995. O contencioso Brasil x Estados Unidos da informática : uma análise sobre formulação da política exterior. São Paulo : Alfa-Ômega-USP.

1998. Mercosul : impactos para trabalhadores e sindicatos. São Paulo : LTR.

WALTZ, K. N. 1987. Teoria della politica internazionale. Bologna : Mulino.

\section{OUTRASFONTES}

GATT. 1986. The General Agreement on Tariffs and Trade. Geneva : GATT. 